\title{
Preparation and Characterization of Copper Oxide Nanoparticles Synthesized via Chemical Precipitation Method
}

\author{
Ismat Zerin Luna ${ }^{1}$, Lutfun Naher Hilary ${ }^{1}$, A. M. Sarwaruddin Chowdhury ${ }^{1}$, M. A. Gafur ${ }^{2}$, \\ Nuruzzaman Khan', Ruhul A. Khan ${ }^{3}$ \\ ${ }^{1}$ Department of Applied Chemistry and Chemical Engineering, Faculty of Engineering and Technology, \\ University of Dhaka, Dhaka, Bangladesh \\ ${ }^{2}$ Pilot Plant and Process Development Center (PP \& PDC), Bangladesh Council of Scientific and Industrial \\ Research, Dhaka, Bangladesh \\ ${ }^{3}$ Institute of Radiation and Polymer Technology, Bangladesh Atomic Energy Commission, Dhaka, Bangladesh \\ Email: ${ }^{\text {ismatzerinluna@gmail.com }}$
}

Received 6 March 2015; accepted 22 March 2015; published 26 March 2015

Copyright (C) 2015 by authors and OALib.

This work is licensed under the Creative Commons Attribution International License (CC BY).

http://creativecommons.org/licenses/by/4.0/

(c) (i) Open Access

\begin{abstract}
Copper oxide nanoparticles (CuO-NPs) were synthesized via chemical precipitation method using copper (II) chloride dihydrate and sodium hydroxide. Then nanoparticles were characterized by using X-ray Diffraction (XRD), Scanning Electron Microscope (SEM), Energy Dispersive X-ray (EDX), and Fourier Transform Infra Red (FTIR) spectroscopy. The XRD patterns and EDX spectra showed that the prepared CuO-NPs were highly pure, crystalline and nano-sized. The SEM image suggested that nano particles were spherical and there was a tendency of agglomerations. The nanoparticles showed interactions between copper and oxygen atoms supported by FTIR studies.
\end{abstract}

\section{Keywords}

Copper Oxide, Nano Particles, Chemical Precipitation, X-Ray Diffraction, SEM

Subject Areas: Chemical Engineering \& Technology, Nanometer Materials

\section{Introduction}

Nanotechnology gained much attention for its vital pioneering role in manipulating materials at the atomic and molecular levels to dramatically alter the product properties. Materials reduced to the nanometric scale display

*Corresponding author.

How to cite this paper: Luna, I.Z., Hilary, L.N., Chowdhury, A.M.S., Gafur, M.A., Khan, N. and Khan, R.A. (2015) Preparation and Characterization of Copper Oxide Nanoparticles Synthesized via Chemical Precipitation Method. Open Access Library Journal, 2: e1409. http://dx.doi.org/10.4236/oalib.1101409 
significantly different properties compared to what they display at the macroscale or microscales. Because of their unique properties, nanomaterials are widely used in a variety of applications. Small amounts of nanoparticles can play a vital role in developing the properties of materials. Nanoparticles are becoming more and more important day by day as they play a beneficial role in a wide variety of scientific fields. In general, the size of a nanoparticle spans the range between 1 and $60 \mathrm{~nm}$. Nanotechnology comprises the design, construction and utilization of functional structures with at least one characteristic dimension measured in nanometers. Currently nanoparticles are widely using in many fields [1]-[9].

The copper oxide nanoparticles (CuO-NPs) possess a wide range of applications. Compared with ordinary copper oxide powder, the nano particles of copper oxide show superior catalytic activity and selectivity. It has excellent antimicrobial activity against various bacterial strains [2]. The CuO-NPs are using in removal of dyes [3], nanoparticulate film fabrications [4], gas sensors [5], semiconductors [6], organic catalysis [7], solar energy transformation [8], and many more. The CuO-NPs also have an application in heat transfer. Thermal conductivity of $\mathrm{CuO}$ based nanofluid is $12.4 \%$ higher in comparison with deionised water [9]. The $\mathrm{CuO}-\mathrm{CeO}_{2}$ nanocomposite is a highly efficient recyclable catalyst for the green synthesis of 1,8-dioxooctahydroxanthenes in water [10]. Graphene oxide-supported CuO-NPs are using to make the nanohybrids catalysts [11]. The CuO-NPs can be synthesized using different methods such as wet chemical method [12], hydrothermal microwave [13], precipitation pyrolysis [14], electrochemical method [15], and microwave irradiation [16].

The aim of this study was to synthesize nanosized copper oxide powder in an easy and effective method and to investigate the cryatallite size, crystallinity, shape, microstructure, composition and interactions between the species of CuO-NPs. In this study, $\mathrm{CuO}-\mathrm{NPs}$ were synthesized via chemical precipitation method followed by annealing at temperatures $200^{\circ} \mathrm{C}, 400^{\circ} \mathrm{C}$ and $600^{\circ} \mathrm{C}$.

\section{Experimental Details}

\subsection{Chemical Reagents}

Copper (II) chloride dihydrate was collected from Merck, India. Sodium hydroxide pellets were purchased from Lobha Chemie, India. Analytical reagent grade chemicals were used in the experiment and they were used without further purification. Distilled water and deionised water were used throughout the experiment for preparing solutions and washing purposes.

\subsection{Synthesis}

To synthesize CuO-NPs via chemical precipitation method, a standard procedure was followed [17]. During the synthesis of CuO-NPs, at first $9.0 \mathrm{~g}$ of copper (II) chloride dihydrate and $5.4 \mathrm{~g}$ of sodium hydroxide pellet were dissolved in ethanol separately. The amuont of ethanol used was as minimum as required to dissolve copper (II) chloride dihydrate and sodium hydroxide separately. Drop wise addition of sodium hydroxide solution to copper (II) cholride dihydrate solution was carried out with constant stirring at room temperature. The color of the solution was turned from green to bluish green and finally to black as the reaction proceeded. The black precipitate was copper hydroxide. The precipitate was filtered by a centrifuge (Eppendorf Refrigerated Centrifuge Model 5702R, Germany). Then washed with ethanol and deionised water to remove the sodium chloride salt solution. After that, the precipitate was dried at about $50^{\circ} \mathrm{C}$ in the dryer. The dried sample was annealed at temperatures at $200^{\circ} \mathrm{C}, 400^{\circ} \mathrm{C}$ and $600^{\circ} \mathrm{C}$ to obtain crystalline CuO-NPs. Then the annealed sample was grinded to get the powdered nanoparticles. The power sample was used to characterize CuO-NPs. Schematically the chemical reaction can be represented as: $\mathrm{CuCl}_{2}+2 \mathrm{NaOH} \rightarrow \mathrm{Cu}(\mathrm{OH})_{2}+2 \mathrm{NaCl}$.

\subsection{Characterization}

The X-ray diffraction (XRD) was carried out to analyze the phase and estimate the crystallite size of the samples using X-ray diffractometer (XRD, Bruker D8 Advance, Germany) with $0.15405 \mathrm{~nm} \mathrm{Cu}-\mathrm{K} \alpha$ radiation source in the $2 \theta$ range from $20^{\circ}$ to $80^{\circ}\left(40 \mathrm{KV}, 40 \mathrm{~mA}\right.$, step size 0.020 , scan rate $\left.0.50 \mathrm{~min}^{-1}\right)$. The XRD patterns with diffraction intensity versus $2 \theta$ were recorded. The surface morphology of the sample was obtained using scanning electron mocroscopy (JEOL, JSM-7600F, Japan). Energy dispersive X-ray (EDX) analysis was carried out with JEOL JSM-7600F for composition analysis. The FTIR spectroscopy of the sample was taken in the region between $500-4000 \mathrm{~cm}^{-1}$ (with Perkin Elmer 1650, USA) on a Thermo-Nicolet Avatar 370 model FTIR in order to 
understand the chemical and structural nature of the CuO-NPs.

\section{Results and Discussion}

\subsection{XRD Patterns}

Figure 1 shows the XRD patterns of $\mathrm{Cu}(\mathrm{OH})_{2}$ complex obtained after drying the precipitate at $50^{\circ} \mathrm{C}$ and also the XRD patterns of CuO-NPs annealed at temperatures at $200^{\circ} \mathrm{C}, 400^{\circ} \mathrm{C}$ and $600^{\circ} \mathrm{C}$. The peaks in the XRD patterns of CuO-NPs were compared with the standard [18].

Figure 2 represents the XRD patterns of CuO-NPs annealed at temperature $600^{\circ} \mathrm{C}$ along with the standard tenorite (CuO). This XRD pattern is similar to the monoclinic phase of $\mathrm{CuO}$ (tenorite) nanoparticles. The intensities and positions of peaks were in good agreement with that of reported values. The experimental results also found similar to the reported diffraction patterns of CuO-NPs [19]. Similarly, it was found that the intensities and positions of peaks in case of CuO-NPs annealed at $200^{\circ} \mathrm{C}$ and $400^{\circ} \mathrm{C}$ were in good agreement with the standard $\mathrm{CuO}$ (tenorite).

From Table 1, it was found that the peak intensity for $\mathrm{CuO}-\mathrm{NPs}$ annealed at $600^{\circ} \mathrm{C}$ was highest and for $\mathrm{CuO}-\mathrm{NPs}$ annealed at $200^{\circ} \mathrm{C}$ the value was the lowest. It was also observed that with increasing the annealing temperature, the intensity of the diffraction peaks became sharper and the degree of crystallinity of CuO-NPs were also increased. At the annealing temperature $200^{\circ} \mathrm{C}$, the cryatallization of $\mathrm{CuO}$ was incomplete. Further increase in annealing temperature to $600^{\circ} \mathrm{C}$ leads towards the completeness of crystallization of $\mathrm{CuO}$. Therefore, the degree of crystallinity of CuO-NPs annealed at $600^{\circ} \mathrm{C}$ was the highest.

From Table 2, it was observed that with increasing annealing temperature the value of full width at half the maximum intensity, $\beta$ increases. The values of lattice parameters (a, b, c) and full width at half the maximum intensity, $\beta$ for CuO-NPs annealed at $600^{\circ} \mathrm{C}$ almost matches with that of standard tenorite (CuO). Therefore, the lattice structure of $\mathrm{CuO}-\mathrm{NPs}$ annealed at $600^{\circ} \mathrm{C}$ is almost base-centered monoclinic [18].

From the values (Table 3), it was noticed that with increasing annealing temperature the average crystallite size of CuO-NPs was increased. With increasing annealing temperature, the atoms in CuO-NPs diffuse across the boundaries of the particles, fusing the particles together and creating one larger particle. Therefore, the crystallite size of the samples increases with increasing the annealing temperature. Higher annealing temperature led to larger crystallite size of CuO-NPs, because higher annealing temperature means higher energy given which results in more oxidation [20].

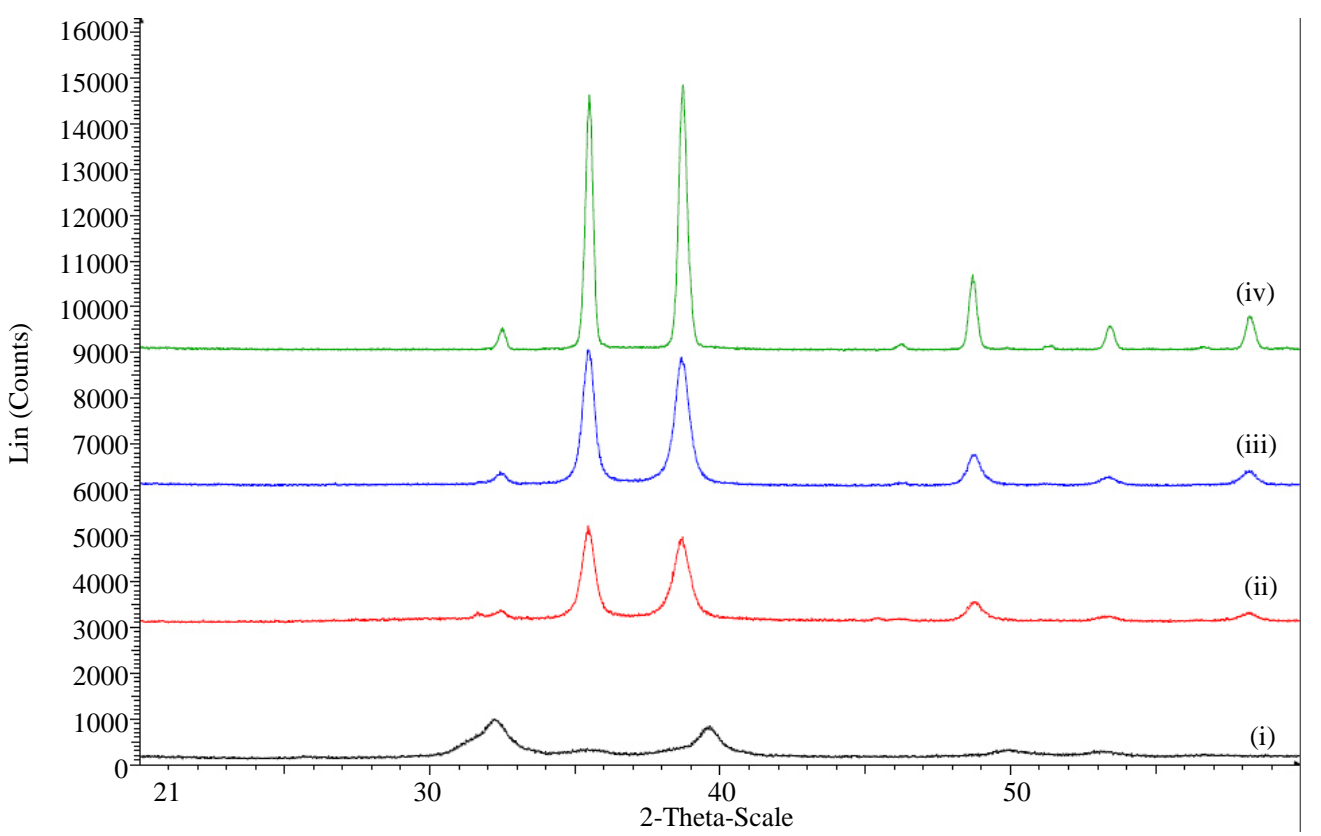

Figure 1. XRD patterns of (i) $\mathrm{Cu}(\mathrm{OH})_{2}$ complex and $\mathrm{CuO}-\mathrm{NPs}$ annealed at (ii) $200^{\circ} \mathrm{C}$, (iii) $400^{\circ} \mathrm{C}$ and (iv) $600^{\circ} \mathrm{C}$. 


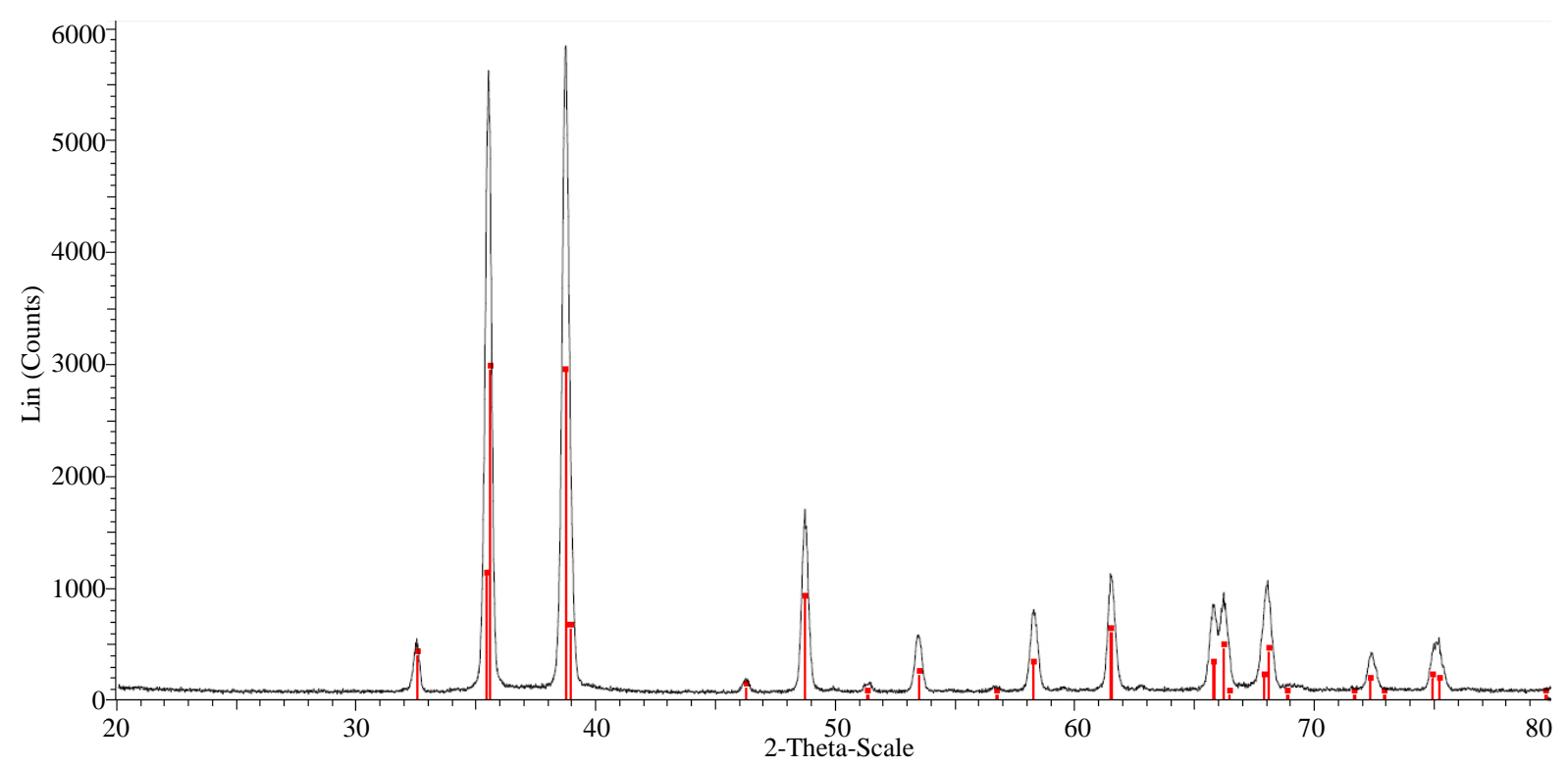

Figure 2. XRD patterns of CuO-NPs annealed at temperature $600^{\circ} \mathrm{C}$. The vertical lines (|) indicate the position and relative intensity of 05-0661 JCPDS card file diffraction peaks for the monoclinic phase.

Table 1. Peak intensities and relative peak intensities of the most prominent peaks in the XRD patterns of CuO-NPs annealed at temperature $200^{\circ} \mathrm{C}, 400^{\circ} \mathrm{C}$ and $600^{\circ} \mathrm{C}$.

\begin{tabular}{ccc}
\hline Samples & Peak intensity (counts) & Relative peak intensity (\%) \\
\hline CuO-NPs annealed at $200^{\circ} \mathrm{C}$ & 1973 & 33.4 \\
CuO-NPs annealed at $400^{\circ} \mathrm{C}$ & 2912 & 49.3 \\
CuO-NPs annealed at $600^{\circ} \mathrm{C}$ & 5901 & 100 \\
\hline
\end{tabular}

Table 2. Lattice parameters (a, b, c) and full width at half the maximum intensity, $\beta$ for CuO-NPs annealed at $200^{\circ} \mathrm{C}, 400^{\circ} \mathrm{C}$ and $600^{\circ} \mathrm{C}$, and standard tenorite $(\mathrm{CuO})$.

\begin{tabular}{ccccc}
\hline Samples & $\mathrm{a}(\mathrm{nm})$ & $\mathrm{b}(\mathrm{nm})$ & $\mathrm{c}(\mathrm{nm})$ & $\beta\left(^{\circ}\right)$ \\
\hline CuO-NPs annealed at $200^{\circ} \mathrm{C}$ & 0.466789 & 0.342411 & 0.511844 & 99.3485 \\
CuO-NPs annealed at $400^{\circ} \mathrm{C}$ & 0.467401 & 0.342340 & 0.512304 & 99.3890 \\
CuO-NPs annealed at $600^{\circ} \mathrm{C}$ & 0.468323 & 0.342244 & 0.512795 & 99.5005 \\
Standard tenorite $(\mathrm{CuO})$ & 0.468830 & 0.342290 & 0.513190 & 99.5100 \\
\hline
\end{tabular}

Table 3. Average crystallite size of CuO-NPs annealed at temperature $200^{\circ} \mathrm{C}, 400^{\circ} \mathrm{C}$ and $600^{\circ} \mathrm{C}$.

\begin{tabular}{cc} 
Samples & Average crystallite size (nm) \\
\hline CuO-NPs annealed at $200^{\circ} \mathrm{C}$ & 15.22 \\
CuO-NPs annealed at $400^{\circ} \mathrm{C}$ & 16.44 \\
CuO-NPs annealed at $600^{\circ} \mathrm{C}$ & 32.50 \\
\hline
\end{tabular}

\subsection{Scanning Electron Microscopic (SEM) Analysis}

Figure 3 represents the SEM image of $\mathrm{CuO}$ nanoparticles obtained by annealing at $600^{\circ} \mathrm{C}$. The SEM image at 25,000× magnifications was collected. From the SEM image of CuO-NPs, it was observed that the particles are well-dispersed spherical, accompanying almost well defined and uniform crystalline structure. There was also a higher tendency of agglomerations. The SEM image supports the formation of regular polyhedron shape for the CuO-NPs. The island growth of the tightly packed spherical arrangement was clearly observed. In some regions, 
the big nanoparticles were surrounded by smaller nanoparticles. Similar SEM images of CuO-NPs were observed and reported [19].

\subsection{Energy Dispersive X-Ray (EDX) Analysis}

Figure 4 showed the EDX analysis of CuO-NPs annealed at $600^{\circ} \mathrm{C}$. The EDX analysis was carried out CuONPs at $10 \mathrm{keV}$. Results revealed the presence of copper (Cu) and oxygen (O) elements in CuO-NPs and the data indicated the nanoparticles were nearly stoichiometric. The weight percent of copper and oxide calculated from EDX analysis were O: 8.73 weight \% (0.525 keV) and Cu: 91.27 weight \% $(0.804 \mathrm{keV})$, respectively. There were no other elemental impurities in the EDX spectra. The EDX result showed the presence of uniform distribution of copper to oxygen with atomic ratio of 1:1 in CuO. This result confirmed the formation of pure CuO-NPs. The elemental analysis of the sample shows that the prepared sample was copper oxide, which is in good concord with the results of XRD. Similar results reported elsewhere [9].

\subsection{Fourier Transform Infra Red (FTIR) Analysis}

Figure 5 showed the FTIR spectra of CuO-NPs annealed at $600^{\circ} \mathrm{C}$. The broad absorption peak at around $3445.89 \mathrm{~cm}^{-1}$ was caused by the adsorbed water molecules. Since the nano crystalline materials possess a high

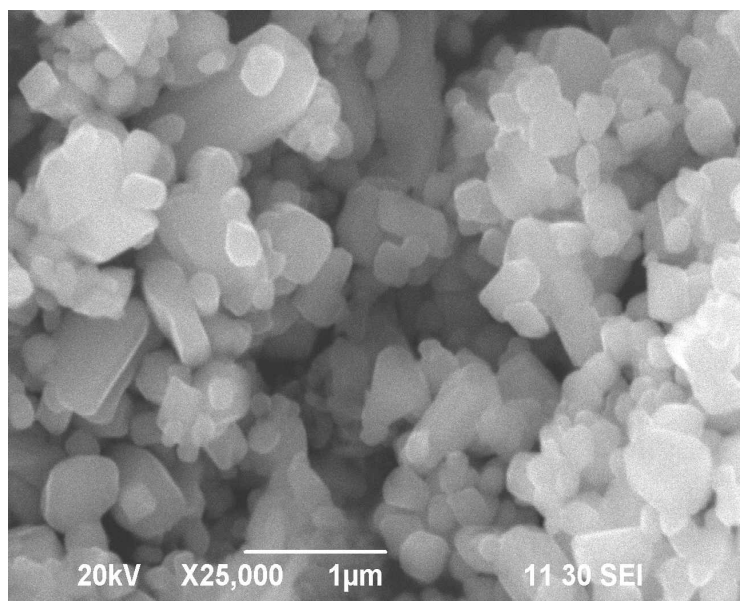

Figure 3. SEM image of CuO-NPs annealed at $600^{\circ} \mathrm{C}$.

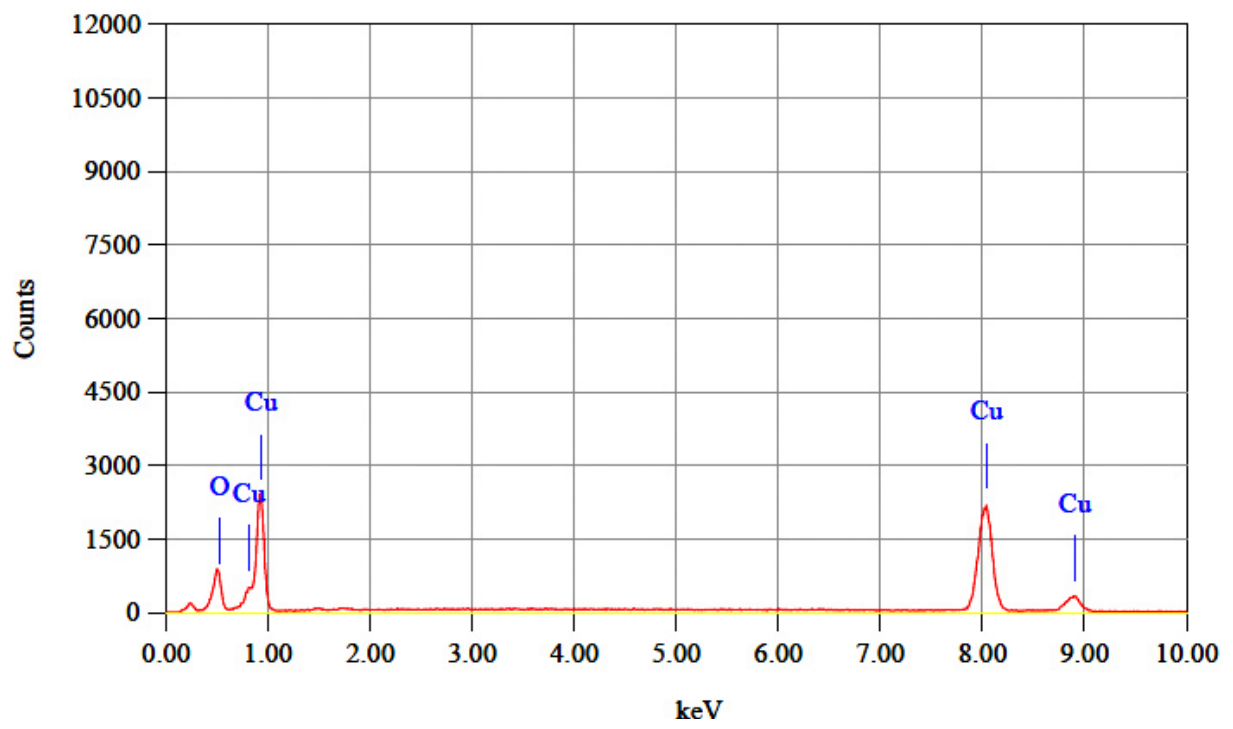

Figure 4. Energy dispersive X-ray analysis of CuO-NPs annealed at $600^{\circ} \mathrm{C}$. 


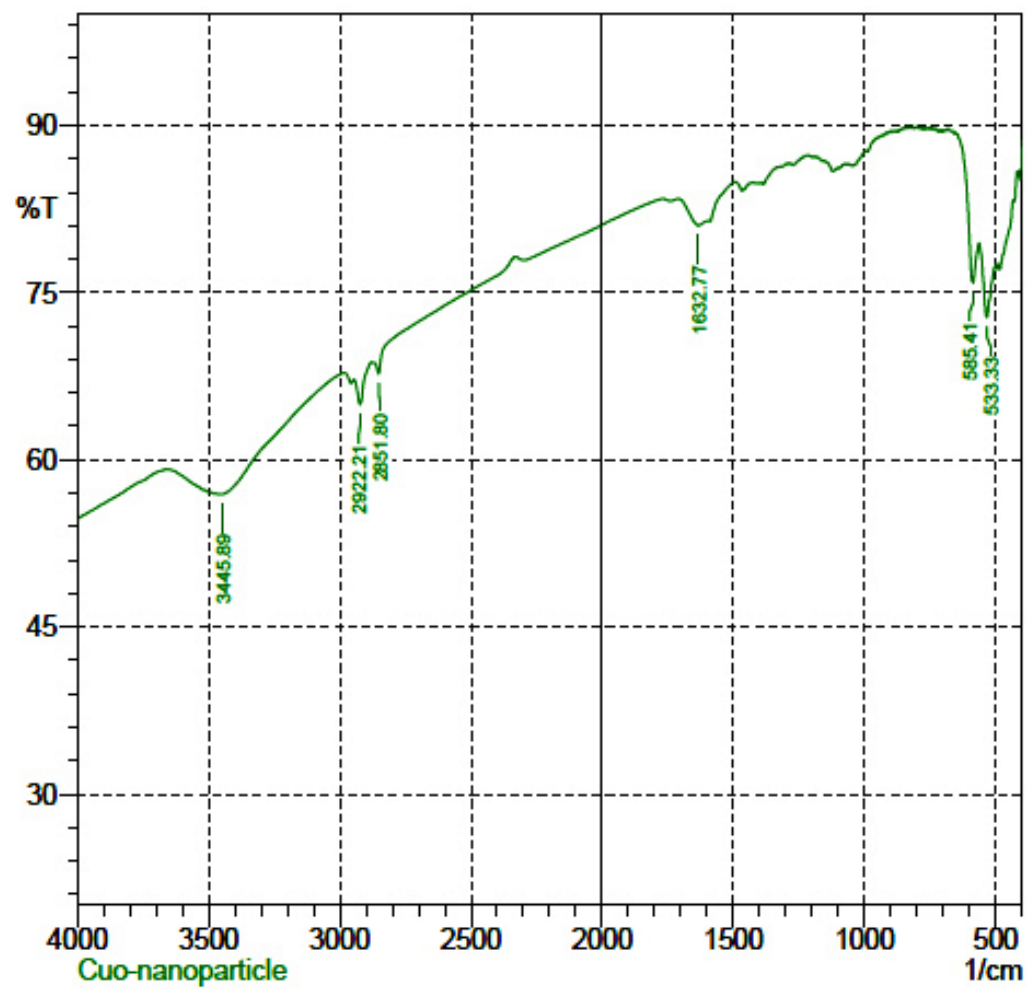

Figure 5. FTIR spectrum of CuO-NPs annealed at $600^{\circ} \mathrm{C}$.

surface to volume ratio, they can absorb moisture. Similar peak at $3434 \mathrm{~cm}^{-1}$ in the FTIR spectra of CuO-NPs are reported [19]. The peak at $2922.21 \mathrm{~cm}^{-1}$ is due to -C-H bond stretching assigned to alkyl group [21]. The region between 2700 and $3750 \mathrm{~cm}^{-1}$ is known as the $\mathrm{OH}$-stretching region [22]. The peaks at 1632.77 may be for the Cu-O symmetrical stretching [23]. The two infrared absorption peaks reveal the vibrational modes of CuO-NPs in the range of $500-700 \mathrm{~cm}^{-1}$. The peaks were observed at $533.33 \mathrm{~cm}^{-1}$ and $585.41 \mathrm{~cm}^{-1}$, respectively. The peak at $533.33 \mathrm{~cm}^{-1}$ could be due to stretching of $\mathrm{Cu}-\mathrm{O}$, which matches up to the $\mathrm{B}_{2 \mathrm{u}}$ mode [24]. The small peak shift in the vibrational modes is associated with the corresponding change in the surface area of the prepared CuO-NPs [25]. The peaks at $533.33 \mathrm{~cm}^{-1}$ and $585.41 \mathrm{~cm}^{-1}$ indicated the formation of the CuO-NPs. These two peaks support the presence of monoclinic phase. No other IR active modes are observed in the range of 500 - $700 \mathrm{~cm}^{-1}$, which totally rules out the existence of $\mathrm{Cu}_{2} \mathrm{O}$. Two peaks at $525 \mathrm{~cm}^{-1}$ and $580 \mathrm{~cm}^{-1}$ in the FTIR spectra reported for $\mathrm{CuO}-\mathrm{NPs}$ which nearly matches with our results [26]. Therefore, the metal-oxygen frequencies observed for CuO-NPs are in close agreement with that of literature values.

\section{Conclusion}

It can be concluded that the syntheis copper oxide nano particles (CuO-NPs) require no expensive ingredients and complicated equipments. This method is easy, less time-consuming and flexible. The XRD pattern indicated cryatalline and monoclinic structure of CuO-NPs. The highest intensity and sharp diffraction peaks with the largest crystallite size $(32.50 \mathrm{~nm})$ were observed for CuO-NPs annealed at $600^{\circ} \mathrm{C}$. The SEM image of CuO-NPs showed that the particles were spherical. The elemental quantification and stoichiometry ratio of CuO-NPs were confirmed by EDX analysis. The FTIR spectra confirmed the presence of metal-oxygen bond. Accumulation of all the experiments confirmed the uniformity of synthesized CuO-NPs.

\section{Acknowledgements}

Sincerely acknowledged to the Ministry of Science and Technology, Government of Bangladesh. Special thanks to the Centre for Advanced Research in Sciences (CARS), University of Dhaka for providing some research facilities. 


\section{References}

[1] Khan, R.A., Beck, S., Dussault, D., Salmieri, S., Bouchard, J. and Lacroix, M. (2013) Mechanical and Barrier Properties of Nanocrystalline Cellulose Reinforced Poly(caprolactone) Composites: Effect of Gamma Radiation. Journal of Applied Polymer Science, 129, 3038-3046. http://dx.doi.org/10.1002/app.38896

[2] Ahamed, M., Alhadlaq, H.A., Khan, M., Karuppiah, P. and Al-Dhabi, N.A. (2014) Synthesis, Characterization, and Antimicrobial Activity of Copper Oxide Nanoparticles. Journal of Nanomaterials, 3, 33-42. http://dx.doi.org/10.1155/2014/637858

[3] Mustafa, G., Tahir, H., Sultan, M. and Akhtar, N. (2013) Synthesis and Characterization of Cupric Oxide (CuO) Nanoparticles and Their Application for the Removal of Dyes. African Journal of Biotechnology, 12, 6650-6662.

[4] Kida, T., Oka, T., Nagano, M., Ishiwata, Y. and Zheng, X.G. (2007) Synthesis and Application of Stable Copper Oxide Nanoparticle Suspensions for Nanoparticulate Film Fabrication. Journal of the American Ceramic Society, 90, 107-112. http://dx.doi.org/10.1111/j.1551-2916.2006.01402.x

[5] Kim, Y.S., Hwang, I.S., Kim, S.J., Lee, C.Y. and Lee, J.H. (2008) CuO Nanowire Gas Sensors for Air Quality Control in Automotive Cabin. Journal of Sensors and Actuators B: Chemical, 135, 298-303. http://dx.doi.org/10.1016/j.snb.2008.08.026

[6] Anandan, S. and Yang, S. (2007) Emergent Methods to Synthesize and Characterize Semiconductor CuO Nanoparticles with Various Morphologies-An Overview. Journal of Experimental Nanoscience, 2, 23-56. http://dx.doi.org/10.1080/17458080601094421

[7] Zhang, W., Guo, F., Wang, F., Zhao, N., Liu, L. and Li, J. (2014) Synthesis of Quinazolines via CuO Nanoparticles Catalyzed Aerobic Oxidative Coupling of Aromatic Alcohols and Amidines. Journal of Organic and Biomolecular Chemistry, 12, 5752-5766. http://dx.doi.org/10.1039/C4OB00569D

[8] Suleiman, M., Mousa, M., Hussein, A., Hammouti, B., Hadda, T.B. and Warad, I. (2013) Copper (II)-Oxide Nanostructures: Synthesis, Characterizations and Their Applications-Review. Journal of Materials and Environmental Science, 5, 792-807.

[9] Manimaran, R., Palaniradja, K., Alagumurthi, N., Sendhilnathan, S. and Hussain, J. (2014) Preparation and Characterization of Copper Oxide Nanofluid for Heat Transfer Applications. Applied Nanoscience, 4, 163-167. http://dx.doi.org/10.1007/s13204-012-0184-7

[10] Albadi, J., Mansournezhad, A. and Abbaszadeh, H. (2013) CuO-CeO $\mathrm{C}_{2}$ Nanocomposite: A Highly Efficient Recyclable Catalyst for the Green Synthesis of 1, 8-Dioxooctahydroxanthenes in Water. Journal of the Chinese Chemical Society, 60, 1193-1206.

[11] Zhou, Z., Lu, C., Wu, X. and Zhang, X. (2013) Cellulose Nanocrystals as a Novel Support for CuO Nanoparticles Catalysts: Facile Synthesis and Their Application to 4-Nitrophenol Reduction. RSC Advances, 3, 26066-26073. http://dx.doi.org/10.1039/c3ra43006e

[12] Joshua, J.P., Krishnan, S., Raj, D., Uthrakumar, R., Laxmi, S. and Das, S.J. (2014) Novel Synthesis of Tenorite (CuO) Nanoparticles by Wet Chemical Method. International Journal of ChemTech Research, 6, 22-33.

[13] Volanti, D., Keyson, D., Cavalcante, L., Simoes, A., Joya, M. and Longo, E. (2008) Synthesis and Characterization of $\mathrm{CuO}$ Flower-Nanostructure Processing by a Domestic Hydrothermal Microwave. Journal of Alloys and Compounds, 459, 537-542. http://dx.doi.org/10.1016/j.jallcom.2007.05.023

[14] Fan, H., Yang, L., Hua, W. and Xie, S. (2004) Controlled Synthesis of Monodispersed CuO Nanocrystals. Nanotechnology, 15, 37-51. http://dx.doi.org/10.1088/0957-4484/15/1/007

[15] Yang, X., Chen, S., Zhao, S., Li, D. and Ma, H. (2003) Synthesis of Copper Nanorods Using Electrochemical Methods. Journal of the Serbian Chemical Society, 68, 843-847. http://dx.doi.org/10.2298/JSC0311843Y

[16] Wang, H., Xu, J.Z., Zhu, J.J. and Chen, H.Y. (2002) Preparation of CuO Nanoparticles by Microwave Irradiation. Journal of Crystal Growth, 244, 88-94. http://dx.doi.org/10.1016/S0022-0248(02)01571-3

[17] Pandey, V., Mishra, G., Verma, S., Wan, M. and Yadav, R. (2012) Synthesis and Ultrasonic Investigations of CuOPVA Nanofluid. Journal of Materials Sciences and Applications, 3, 664-653. http://dx.doi.org/10.4236/msa.2012.39097

[18] International Centre for Diffraction Data (ICDD) (2000) Joint Committee on Powder Diffraction Standards, Diffraction Data File No. 05-0661, 12-23.

[19] Radhakrishnan, A.A. and Beena, B.B. (2014) Structural and Optical Absorption Analysis of CuO Nanoparticles. Indian Journal of Advances in Chemical Science, 2, 158-161.

[20] Raksa, P., Kittikunodom, S., Choopun, S., Chairungsri, T., Mangkorntong, P. and Mankorntong, N. (2005) CuO Nanowires by Oxidation Reaction. CMU Journal of Nanotechnology, 4, 1-5. 
[21] Kumar, H. and Rani, R. (2006) Antibacterial Study of Copper Oxide Nanoparticles Synthesized by Microemulsion. Journal of Raman Spectroscopy, 36, 562-574.

[22] Kloprogge, J.T., Hickey, L. and Frost, R.L. (2004) FT-Raman and FT-IR Spectroscopic Study of Synthetic Mg/Zn/AlHydrotalcites. Journal of Raman Spectroscopy, 35, 967-974. http://dx.doi.org/10.1002/jrs.1244

[23] Markova-Deneva, I. (2010) Infrared Spectroscopy Investigation of Metallic Nanoparticles Based on Copper, Cobalt, and Nickel Synthesized through Borohydride Reduction Method. Journal of the University of Chemical Technology and Metallurgy, 45, 351-378.

[24] Karthik, K., Victor Jaya, N., Kanagaraj, M. and Arumugam, S. (2011) Temperature-Dependent Magnetic Anomalies of CuO Nanoparticles. Solid State Communications, 151, 564-568. http://dx.doi.org/10.1016/j.ssc.2011.01.008

[25] Chen, L.J., Li, G.S. and Li, L.P. (2008) CuO Nanocrystals in Thermal Decomposition of Ammonium Perchlorate. Journal of Thermal Analysis and Calorimetry, 91, 581-587. http://dx.doi.org/10.1007/s10973-007-8496-7

[26] Padil, V.V.T. and Cernik, M. (2013) Green Synthesis of Copper Oxide Nanoparticles Using Gum Karaya as a Biotemplate and Their Antibacterial Application. International Journal of Nanomedicine, 8, 889-898. 